Research article

\title{
TIMP-2 mediates the anti-invasive effects of the nitric oxide-releasing prodrug JS-K in breast cancer cells
}

\author{
Ann-Marie Simeone ${ }^{1}$, Vanity McMurtry ${ }^{1}$, René Nieves-Alicea ${ }^{1}$, Joseph E Saavedra ${ }^{2}$, \\ Larry K Keefer ${ }^{3}$, Marcella M Johnson ${ }^{4}$ and Ana M Tari ${ }^{1}$
}

\begin{abstract}
1Department of Experimental Therapeutics, The University of Texas MD Anderson Cancer Center, Houston, TX 77030, USA
${ }^{2}$ Basic Research Program, SAIC-Frederick, National Cancer Institute at Frederick, Frederick, MD 21702, USA

${ }^{3}$ Laboratory of Comparative Carcinogenesis, National Cancer Institute at Frederick, Frederick, MD 21702, USA

${ }^{4}$ Department of Biostatistics \& Applied Mathematics, The University of Texas MD Anderson Cancer Center, Houston, TX 77030, USA
\end{abstract}

Corresponding author: Ana M Tari, atari@mdanderson.org

Received: 18 Apr 2007 Revisions requested: 11 Jun 2007 Revisions received: 7 Apr 2008 Accepted: 12 May 2008 Published: 12 May 2008

Breast Cancer Research 2008, 10:R44 (doi:10.1186/bcr2095)

This article is online at: http://breast-cancer-research.com/content/10/3/R44

(c) 2008 Simeone et al.; licensee BioMed Central Ltd.

This is an open access article distributed under the terms of the Creative Commons Attribution License (http://creativecommons.org/licenses/by/2.0), which permits unrestricted use, distribution, and reproduction in any medium, provided the original work is properly cited.

\begin{abstract}
Introduction Tumor invasion and metastasis remain a major cause of mortality in breast cancer patients. High concentrations of nitric oxide (NO) suppress tumor invasion and metastasis in vivo. NO prodrugs generate large amounts of $\mathrm{NO}$ upon metabolism by appropriate intracellular enzymes, and therefore could have potential in the prevention and therapy of metastatic breast cancer.

Methods The present study was designed to determine the effects of the NO-releasing prodrug O2-(2,4-dinitrophenyl) 1[(4-ethoxycarbonyl)piperazin-1-yl]diazen-1-ium-1,2-diolate (JS$\mathrm{K})$ on breast cancer invasion and the mechanisms involved. MDA-MB-231, MDA-MB-231/F10, and MCF-7/COX-2 were the three breast cancer cell lines tested. NO levels were determined spectrophotometrically using a NO assay kit. Invasion and the expression of matrix metalloproteinases (MMPs) and tissue inhibitor of MMPs were determined using Matrigel invasion assays, an MMP array kit and ELISAs. The activity and expression of extracellular signal-regulated kinase 1/ 2, p38, and c-Jun $\mathrm{N}$-terminal kinase mitogen-activated protein kinases were determined using western blot analyses.
\end{abstract}

$$
\text { kinases were determined using western blot analyses. }
$$

\section{Introduction}

Breast cancer is the most common cancer detected in women, accounting for nearly one out of every three cancers diagnosed in the United States. Metastasis is the primary cause of breast cancer mortality. The 5-year survival rate for women diagnosed with localized breast cancer is $98 \%$, which
Results Under conditions by which JS-K was not cytotoxic, JS$\mathrm{K}$ significantly decreased $(P<0.05)$ the invasiveness of breast cancer cells across the Matrigel basement membrane, which was directly correlated with NO production. JS-43-126, a nonNO-releasing analog of JS-K, had no effect on NO levels or invasion. JS-K increased $(P<0.05)$ TIMP-2 production, and blocking TIMP-2 activity with a neutralizing antibody significantly increased $(P<0.05)$ the invasive activity of JS-K-treated cells across Matrigel. JS-K decreased p38 activity, whereas the activity and the expression of extracellular signal-regulated kinase $1 / 2$ and c-Jun $\mathrm{N}$-terminal kinase were unaffected.

Conclusion We report the novel findings that JS-K inhibits breast cancer invasion across the Matrigel basement membrane, and NO production is vital for this activity. Upregulation of TIMP-2 production is one mechanism by which JS-K mediates its anti-invasive effects. JS-K and other NO prodrugs may represent an innovative biological approach in the prevention and treatment of metastatic breast cancer.

COX-2 = cyclooxygenase-2; DMEM = Dulbecco's modified Eagle's medium; ELISA = enzyme-linked immunosorbent assay; ERK1/2 = extracellular signal-regulated kinase $1 / 2 ; \mathrm{FBS}=$ fetal bovine serum; GST = glutathione S-transferase; JNK = c-Jun N-terminal kinase; JS-K $=\mathrm{O}^{2}$ - $(2,4-$ dinitrophenyl) 1- [(4-ethoxycarbonyl)piperazin-1-yl]diazen-1-ium-1,2-diolate; MMP = matrix metalloproteinase; MTS = 3-(4,5-dimethylthiazol-2-yl)-5-(3-carboxymethoxyphenyl)-2-(4-sulfophenyl)-2H-tetrazolium; $\mathrm{NO}=$ nitric oxide; $\mathrm{NOS}=$ nitric oxide synthase; TIMP $=$ tissue inhibitor of matrix metalloproteinase. 
The free radical nitric oxide (NO) plays an important role in regulating tumor growth and metastasis. The amount of NO produced depends on the expression of nitric oxide synthase (NOS) isoforms. NOSI and NOSIII are expressed constitutively and produce trace amounts of NO. NOSII is the inducible isoform and can generate large amounts of NO.

Low concentrations of NOSIII-derived NO promoted the growth, invasion, and metastasis of murine mammary tumors $[2,3]$. In contrast, high levels of NOSII-mediated NO have been shown to suppress tumorigenesis and metastasis in vivo [4-8]. EMT-6] murine breast carcinoma cells, which constitutively expressed inducible NOSII and secreted high levels of NO, had a lower metastatic potential than NOSIl-deficient EMT-6H cells when injected into mice [6]. EMT-6H cells induced the formation of numerous metastases in the lungs of all the injected mice, while the number of mice with lung metastases and the number of metastases per lung were lower in the EMT-6J group [6]. Similarly, pancreatic cells transduced with wild-type NOSI/ suppressed tumor growth and distant metastasis to the liver in an orthotopic xenograft model [8].

We previously demonstrated that breast cancer cells possess intrinsic resistance mechanisms that can prevent the induction of NOSII $[9,10]$; any chemopreventive or therapeutic strategy designed to produce high NO levels in such cells should therefore not depend on NOSII induction. Given the suppressive effects of high levels of NO on tumorigenesis and metastasis, drugs that supply NO exogenously could have potential in breast cancer therapy and chemoprevention. The challenge is to deliver $\mathrm{NO}$ in a sustained and controlled manner.

NO donors that spontaneously generate large amounts of NO independent of NOSII induction are activated at physiological $\mathrm{pH}$ and can induce NO-mediated systemic hypotension. NO prodrugs are another type of NOSII-independent NO-releasing agent. NO prodrugs do not release NO spontaneously, but rather can be activated to generate high concentrations of NO upon metabolism by intracellular enzyme targets. Arylated diazeniumdiolates have been designed to be activated for NO release by reaction with glutathione S-transferases (GSTs). GSTs are a superfamily of enzymes that detoxify xenobiotics by conjugating them to glutathione and increasing their cellular excretion. Among the major isoforms $(\alpha, \mu, \pi)$, GST- $\pi$ is expressed at the highest concentration in breast tumors $[11,12]$. The expression of GST- $\pi$ is associated with more aggressive tumors, poor prognosis, increased risk of relapse, and decreased disease-free survival in breast cancer patients $[13,14]$.

O2-(2,4-dinitrophenyl) 1- [(4-ethoxycarbonyl)piperazin-1yl]diazen-1-ium-1,2-diolate (JS-K), a diazeniumdiolate activated to release high levels of NO by GST enzymes [15], has been shown to inhibit cancer cell growth in vitro and in vivo
[15-19]. Whether JS-K can suppress cancer invasion, however, is not known. In the present article we report the novel findings that JS-K inhibits the invasive activity of breast cancer cells across the Matrigel basement membrane at doses by which JS-K was not cytotoxic, and that increasing TIMP-2 production is one mechanism by which JS-K mediates its antiinvasive effects. The results presented here have a bearing on the potential for NO prodrugs to be used in the prevention and therapy of metastatic breast cancer.

\section{Materials and methods \\ Reagents}

Matrigel and type I collagen were purchased from BD Biosciences (Bedford, MA, USA) and Sigma-Aldrich Chemical Co (St. Louis, MO, USA), respectively. Hema-3 was purchased from Fisher Scientific (Middleton, VA, USA). Rabbit polyclonal GST- $\pi$ and GST- $\alpha$ antibodies were purchased from EMD Biosciences (La Jolla, CA, USA). $\beta$-actin monoclonal antibody was purchased from Sigma-Aldrich Chemical Co. The polyclonal antibody to TIMP-2 was purchased from R \& D Systems (Minneapolis, MN, USA). Phospho(Thr202/Tyr204)extracellular signal-regulated kinase 1/2 (ERK1/2), ERK1/2, phospho(Thr $\left.{ }^{180 / T y r}{ }^{182}\right)$-p38, p38, phospho(Thr $\left.{ }^{183 / T y r}{ }^{185}\right)$-cJun $\mathrm{N}$-terminal kinase (JNK), and JNK antibodies were purchased from Cell Signaling (Beverly, MA, USA).

JS-K [20] and JS-43-126 [21], a JS-K analog that does not release NO, were prepared as previously described. Stock solutions of JS-K and JS-43-126 were prepared in dimethylsulfoxide and were stored at $-20^{\circ} \mathrm{C}$. The structures of JS-K and JS-43-126 are presented in Figure 1.

\section{Figure 1}

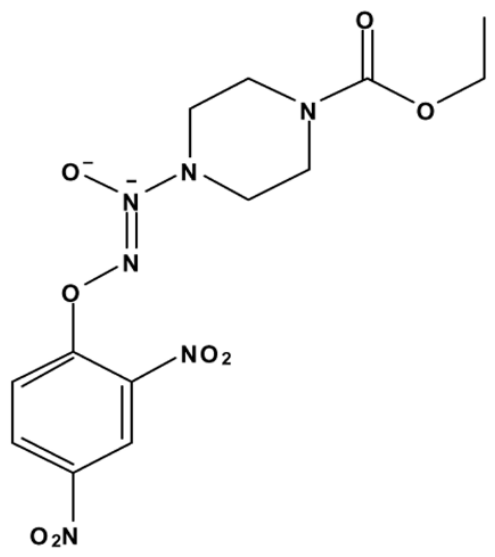

JS-K<smiles>CCOC(=O)N1CCN(c2ccc([N+](=O)[O-])cc2[N+](=O)[O-])CC1</smiles>

JS-43-126
Structures of JS-K and JS-43-126, a non-nitric oxide-releasing JS-K analog. 


\section{Cell lines and culture conditions}

The human MDA-MB-231 breast cancer cell line was obtained from American Type Cell Culture (Manassas, VA, USA). The MDA-MB-231 cell line is an estrogen-independent, highly metastatic human breast cancer cell line. Breast cancer commonly metastasizes to the skeletal system. MDA-MB-231/F10 (F10) is a bone metastatic derivative of MDA-MB-231 cells selected in vivo by repeated intracardiac injections of the MDA-MB231 cells into female nude mice until no micrometastases were detected histologically in any organs other than bone [22]. The F10 cell line was kindly provided by Dr Toshiyuki Yoneda (The University of Texas Health Science Center, San Antonio, TX, USA).

Breast cancer also commonly metastasizes to lymph nodes. Elevated COX-2 expression in invasive breast tumor is associated with lymph node metastasis [23-25]. MCF-7/COX-2 cells are estrogen-dependent MCF-7 cells stably transfected with plasmids encoding the human COX-2 gene [26]. The parental MCF-7 cells are poorly invasive but the MCF-7/COX2 cells are highly invasive [27].

The MDA-MB-231 and F10 cell lines were cultured in DMEM/ F12 (Invitrogen, Carlsbad, CA, USA) supplemented with 5\% heat-inactivated FBS) (Invitrogen) at $37^{\circ} \mathrm{C}$ under $5 \%$ carbon dioxide in a humidified incubator. MCF-7/COX-2 cells were continuously cultured in DMEM/F12 medium containing 5\% FBS and $500 \mu \mathrm{g} / \mathrm{ml}$ antibiotic G418 (Invitrogen).

\section{Western blot analysis}

Protein lysates $(50 \mu \mathrm{g})$ from untreated exponentially growing MDA-MB-231, F10, and MCF-7/COX-2 breast cancer cells were loaded onto $15 \%$ polyacrylamide gels to determine the expression of GST- $\pi$ and GST- $\alpha$. The MDA-MB-231 cells (3 $\times 10^{5}$ cells), F10 cells ( $3 \times 10^{5}$ cells), and MCF-7/COX- 2 cells ( $4 \times 10^{5}$ cells) were plated in T25 flasks in $5 \mathrm{ml}$ DMEM/F12 medium supplemented with $5 \%$ FBS. The next day, cells were treated with JS-K $(0.5$ and $1.0 \mu \mathrm{M})$ for 24 hours. Protein lysates $(30 \mu \mathrm{g})$ were loaded onto $12 \%$ polyacrylamide gels to determine the activity and expression of ERK1/2, p38, and JNK mitogen-activated protein kinases. Proteins were electrophoresed and electrotransferred as described previously [10]. Membranes were incubated with the appropriate antibodies. $\beta$-actin was used as a loading control. Protein bands were visualized by enhanced chemiluminescence (Kirkgaard \& Perry Laboratories, Gaithersburg, MD, USA). Images were scanned and quantified by an Alpha Innotech densitometer using the Alpha Imager application program (San Leandro, CA, USA).

\section{Nitric oxide assay}

The MDA-MB-231 cells $\left(3 \times 10^{5}\right.$ cells $)$, F10 cells $\left(3 \times 10^{5}\right.$ cells), and MCF-7/COX-2 cells $\left(4 \times 10^{5}\right.$ cells) were plated in T25 flasks in $5 \mathrm{ml}$ DMEM/F12 medium supplemented with $5 \%$ FBS. The next day, cells were treated with JS-K (0.5 and 1.0 $\mu \mathrm{M})$ or JS-43-126 (0.5 and $1.0 \mu \mathrm{M})$ for 72 hours. The medium was recovered, centrifuged for 5 minutes, and concentrated using spin columns with 10-kDa-cutoff filters (Millipore, Bedford, MA, USA). Total NO was determined in the conditioned concentrated supernatants by quantifying nitrite, the stable end product of NO oxidation, spectrophotometrically using a colorimetric nonenzymatic nitric oxide assay kit (Oxford Biomedical Research, Oxford, MI, USA) as described previously [9]. Cell growth was determined by total live cell counts using trypan blue exclusion. Nitrite values were normalized for total cell counts and expressed as picomoles per $10^{6}$ cells. The experiments were performed in triplicate wells.

\section{Proliferation assay}

One hundred microliters of Matrigel $(0.7 \mathrm{mg} / \mathrm{ml})$ were added to each well of 96-well plates. The MDA-MB-231 cells, F10 cells, and MCF/COX- 2 cells $\left(1 \times 10^{4}\right.$ cells resuspended in $100 \mu \mathrm{l}$ medium) were added to Matrigel-coated wells. The next day, JS-K $(0,0.5$ and $1.0 \mu \mathrm{M})$ was added to cells in pentaplicate wells. After 3 days of incubation, cell proliferation was determined by the Promega (Madison, WI, USA) Celltiter $96^{\circledR}$ $\mathrm{AQ}_{\text {ueous }}$ nonradioactive cell proliferation assay. The CellTiter $96{ }^{\circledR} \mathrm{AO}_{\text {ueous }}$ Assay is composed of 3-(4,5-dimethylthiazol-2yl)-5-(3-carboxymethoxyphenyl)-2-(4-sulfophenyl)-2H-tetrazolium (MTS) and the electron coupling reagent phenazine methosulfate. MTS is reduced by live cells into a formazan product, whose absorbance can be read at $490 \mathrm{~nm}$. The quantity of formazan product is directly proportional to the number of living cells in culture. The absorbance of the formazan product was read within 2 hours after the MTS/phenazine methosulfate dye addition. Cell proliferation was expressed as the percentage of untreated cells. The experiments were repeated twice.

\section{Invasion assay}

The effect of JS-K on breast cancer invasion was determined in vitro using modified Boyden chamber assays as previously described [28]. Briefly, six-well plate transwell inserts with 8$\mu \mathrm{m}$ pore-size polycarbonate filters (Fisher Scientific) were coated with Matrigel $(0.7 \mathrm{mg} / \mathrm{ml})$ or type I collagen $(20 \mu \mathrm{g} / \mathrm{ml})$ in cold serum-free DMEM/F12 medium and were placed at room temperature for 40 minutes. Cells were trypsinized, resuspended in serum-supplemented media, and were then counted.

Cells were then washed three times with serum-free medium. The MDA-MB-231 cells $\left(3 \times 10^{5}\right.$ cells), F10 cells $\left(3 \times 10^{5}\right.$ cells), and MCF-7/COX-2 cells ( $4 \times 10^{5}$ cells), resuspended in $500 \mu \mathrm{l}$, were added into the Matrigel-coated or the collagencoated transwell inserts and were incubated for 72 hours in the absence or presence of JS-K $(0.5$ and $1.0 \mu \mathrm{M})$ or JS-43$126(0.5$ and $1.0 \mu \mathrm{M})$. The lower chambers were filled with 2 $\mathrm{ml} \mathrm{DMEM/F12} \mathrm{medium} \mathrm{supplemented} \mathrm{with} \mathrm{5 \%} \mathrm{FBS.} \mathrm{After}$ incubation, noninvading cells on the upper surface of the filter were removed with cotton swabs. Cells that had invaded through the pores onto the lower side of the filter were fixed, stained with Hema-3, and photographed. The invaded cells 
were counted in five fields for each filter under a light microscope at $40 \times$ magnification. The invasiveness of the cells was expressed as the mean number of cells that had invaded to the lower side of the filter. The experiments were performed in triplicate wells and were repeated twice.

To determine the importance of TIMP-2 in JS-K-mediated antiinvasive effects, TIMP-2 activity was blocked with a neutralizing antibody (R \& D Systems). The MDA-MB-231, F10, and MCF-7/COX-2 cells were treated with $1 \mu \mathrm{M}$ JS-K in the presence or absence of the anti-TIMP-2 antibody $(2.5 \mu \mathrm{g} / \mathrm{ml})$ for 72 hours in a Matrigel invasion assay. The experiments were performed in triplicate wells and were repeated twice.

\section{Collection of conditioned medium supernatant}

The MDA-MB-231 cells $\left(3 \times 10^{5}\right.$ cells $), F 10$ cells $\left(3 \times 10^{5}\right.$ cells), and MCF-7/COX-2 cells $\left(4 \times 10^{5}\right.$ cells) were plated in T25 flasks in $5 \mathrm{ml}$ DMEM/F12 medium supplemented with $5 \%$ FBS. The next day, cells were treated with JS-K (0.5 and 1.0 $\mu \mathrm{M})$ or JS-43-126 (0.5 and $1.0 \mu \mathrm{M})$ for 24 hours. The medium in each flask was then replaced with serum-free medium and the flasks were incubated for an additional 24 hours. The medium was recovered, centrifuged for 5 minutes, and concentrated using spin columns with $10-\mathrm{kDa}$-cutoff filters. The medium collected was used for the matrix metalloproteinase (MMP) array and to determine the expression of TIMP-2.

\section{Human matrix metalloproteinase array}

The expression of MMPs and TIMPs in the conditioned medium supernatant was qualitatively screened using a human MMP array kit (RayBiotech, Norcross, GA, USA). The array allows for the simultaneous detection of seven MMPs (MMP1, MMP-2, MMP-3, MMP-8, MMP-9, MMP-10, MMP-13) and three TIMPs (TIMP-1, TIMP-2, TIMP-4). Images were scanned using an Alpha Imager application program.

\section{Enzyme-linked immunosorbent assays for TIMP-2}

The concentration of TIMP-2 in the conditioned medium supernatant was determined using a TIMP-2 ELISA kit (EMD Biosciences). The concentration of TIMP-2 was normalized to the cell number and was expressed as nanograms per milliliter per $10^{6}$ cells. The experiments were performed in triplicate wells and were repeated three times.

\section{Statistical analyses}

For statistical analysis of the invasion experiments, the Shapiro-Wilk test was first performed to assess the normality of assumption data. Given that the data were normally distributed, two-sample $t$ tests were performed for each of the three cell lines to compare the number of invading cells for the untreated group with the number of invading cells for each dose of JS-K and JS-43-126. The number of invading cells was also compared between the two doses of JS-K and JS43-126. Two-sample $t$ tests were also used to compare the number of invading cells for the group treated with JS-K with the number of invading cells for the group treated with JS-K in the presence of the anti-TIMP-2 antibody for each cell line.

The significance level for each individual comparison $(0.05 / 3$ $=0.0167$ ) was adjusted by the Bonferroni method to account for multiple testing within each cell line to achieve an overall significance level of $5 \%$. All analyses were performed using SAS software (SAS Institute, Inc., Cary, NC, USA). The same statistical analyses were used to compare the NO and TIMP2 levels of untreated cells with those treated with JS-K or JS43-126 as appropriate.

\section{Results \\ Expression of GST- $\pi$ and GST- $\alpha$ in breast cancer cell lines}

JS-K is activated to release NO by GST enzymes [15]; the expression of GST- $\pi$ and GST- $\alpha$ in MDA-MB-231, F10, and MCF-7/COX-2 breast cancer cells was therefore determined. The MDA-MB-231 and F10 cells expressed GST- $\pi$ and GST$\alpha$, but GST- $\pi$ was the predominant isoform (Figure 2). MCF-7/ COX-2 cells expressed GST- $\alpha$ but not GST- $\pi$ (Figure 2).

\section{JS-K, but not JS-43-126, increases nitric oxide levels in breast cancer cells}

$\mathrm{NO}$ levels were determined in untreated and JS-K-treated MDA-MB-231, F10, and MCF-7/COX-2 cells to confirm drug activation. The NO production was significantly increased $(P$ $<0.05$ ) in the three cell lines as a result of JS-K treatment (Figure 3).

The NO levels were 2.1 -fold and fourfold higher $(P<0.05)$ in MDA-MB-231 cells treated with 0.5 and $1 \mu \mathrm{M}$ JS-K, respectively (Figure 3). The NO levels were increased $(P<0.05)$ 5.8fold and 6.1 -fold at the 0.5 and $1 \mu \mathrm{M}$ concentrations of JS-K in F10 cells, respectively (Figure 3 ). Although the two concentrations of JS-K did not differ $(P>0.05)$ in the $\mathrm{NO}$ levels produced, the $\mathrm{NO}$ levels of JS-K-treated F10 cells were

Figure 2

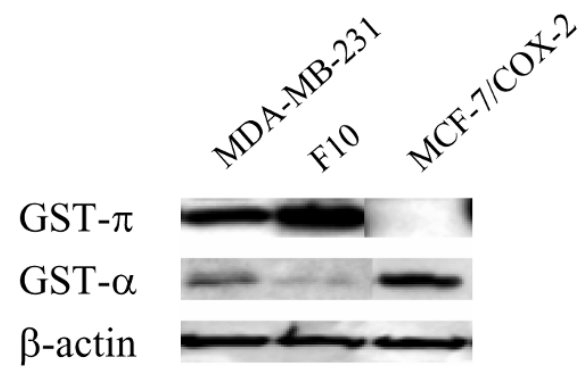

Expression of glutathione S-transferase $\pi$ and $\alpha$ isoforms in breast cancer cell lines. Expression of glutathione S-transferase (GST)- $\pi$ and GST- $\alpha$ isoforms in breast cancer cell lines. Protein lysates were obtained from exponentially growing MDA-MB-231, F10, and MCF-7/ COX- 2 cells. Western blot analyses using polyclonal GST- $\pi$ and GST$\alpha$ antibodies were performed. $\beta$-actin was used as a loading control. 
Figure 3

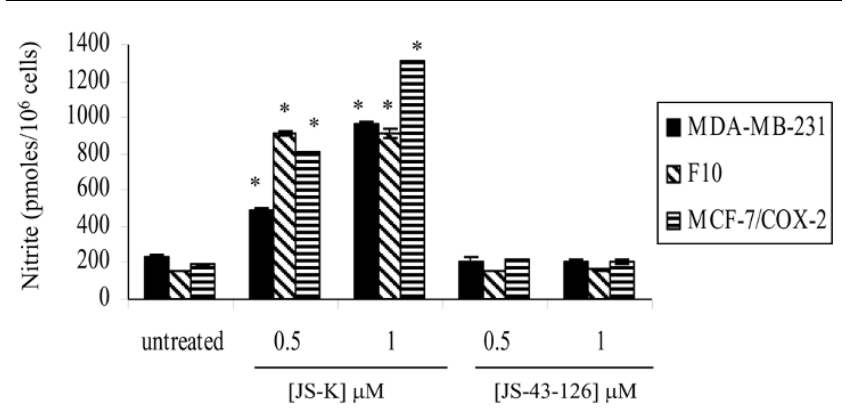

JS-K, but not JS-43-126, increases nitric oxide production in breast cancer cells. Conditioned medium supernatant was collected from MDA-MB-231, F10, and MCF-7/COX-2 cells treated in the absence or presence of JS-K or JS-43-126 for 72 hours. Total nitric oxide (NO) was determined by quantifying nitrite, the stable end product of $\mathrm{NO}$ oxidation, spectrophotometrically using a colorimetric nonenzymatic nitric oxide assay kit. Nitrite values were normalized for total cell counts and expressed as picomoles per $10^{6} \mathrm{cells}$. Columns indicate the mean of triplicate wells \pm standard deviation. *Significant increase in NO levels relative to untreated cells, $P<0.05$.

significantly higher $(P<0.05)$ in comparison with untreated cells (Figure 3 ). The NO levels were increased $(P<0.05) 4.9$ fold and sevenfold in MCF-7/COX-2 cells at the 0.5 and $1 \mu \mathrm{M}$ concentrations of JS-K, respectively (Figure 3 ). JS-K can therefore be activated to release $\mathrm{NO}$ by breast cancer cells. In contrast, NO production was not different $(P>0.05)$ between untreated cells and those treated with JS-43-126 for each of the three cell lines (Figure 3).

\section{JS-K, but not JS-43-126, decreases breast cancer invasion across a Matrigel-coated membrane}

The invasion of cancer cells through basement membranes is an essential step in cancer metastasis. Matrigel is a solubilized basement membrane preparation extracted from the Engelbreth-Holm-Swarm mouse sarcoma, a tumor rich in extracellular matrix proteins. The major component of Matrigel is laminin. Matrigel has been used by numerous groups to assay the invasive activity of tumor cells across the basement membrane [29-31].

Matrigel invasion assays were performed to determine the effect of JS-K on the invasiveness of breast cancer cells across the basement membrane. Untreated MDA-MB-231, F10, and MCF-7/COX-2 cells displayed a high invasive capacity on Matrigel (Figure 4a). In all cell lines, JS-K significantly $(P<0.05)$ reduced the number of invasive cells (Figure $4 \mathrm{a}, \mathrm{b})$. The number of invaded MDA-MB-231 cells was decreased $(P<0.05) 37 \%$ and $85 \%$ at the 0.5 and $1 \mu \mathrm{M}$ doses of JS-K, respectively (Figure $4 \mathrm{~b}$ ). The number of invaded $\mathrm{F} 10$ cells was reduced $(P<0.05) 63 \%$ and $76 \%$ by the 0.5 and $1 \mu \mathrm{M}$ doses of JS-K, respectively (Figure $4 \mathrm{~b}$ ). The two doses of JS-K, however, did not have significantly different $(P>0.05)$ anti-invasive effects in F10 cells (Figure $4 \mathrm{~b})$. In MCF-7/COX-2 cells, JS-K reduced $(P<0.05)$ the number of invaded cells $49 \%$ and $75 \%$ at the 0.5 and $1 \mu \mathrm{M}$ doses of JS$\mathrm{K}$, respectively (Figure $4 \mathrm{~b}$ ). In contrast, the invasiveness of the three cell lines was unaffected by treatment with JS-43-126 (Figure 4b). JS-K can therefore decrease breast cancer invasion across Matrigel, and this is dependent on NO production.

JS-K has been shown to induce growth inhibition in cancer cells [15-19]. We determined the effects of JS-K on the proliferation of breast cancer cells grown on Matrigel, in order to mimic the conditions used in the Matrigel invasion assays. The 0.5 and $1.0 \mu \mathrm{M}$ doses of JS-K induced $<20 \%$ growth inhibition in any of the breast cancer cell lines (Figure 4c). JS-Kmediated decreases in the Matrigel invasion assays were therefore not the result of growth inhibition.

Bone is the most prevalent site of first distant relapse of breast cancer, with as many as $85 \%$ of patients with advanced breast cancer suffering from bone metastases [32]. Type I collagen is the most abundant protein within the bone, making up $>90 \%$ of the total protein within this site [33]. Type I collagen has been used to assay the invasive activity of tumor cells across the bone matrix [34,35]. A type I collagen invasion assay was performed to determine whether JS-K may inhibit the invasiveness of breast cancer cells across the bone matrix. The conditions for the collagen invasion assay were identical to those of the Matrigel invasion assay, except that type I collagen was used to coat the transwell insert. The MDA-MB-231 and F10 cells displayed a high invasive capacity on type I collagen (Figure $4 d$ ), but MCF-7/COX-2 cells did not (data not shown). JS$\mathrm{K}$ did not reduce the invasiveness of breast cancer cells across type I collagen-coated insert (Figure 4d). These data indicate that JS-K can block breast cancer cells from invading through Matrigel but not through type I collagen, suggesting that JS-K can block breast cancer invasion through the basement membrane but not through the bone matrix.

\section{JS-K increases TIMP-2 production to block breast cancer cells from invading through Matrigel}

MMPs, which are involved in the degradation of the basement membrane, are essential to the invasive process. In contrast, TIMPs regulate the activity of MMPs and protect the basement membrane from proteolysis. A human MMP array was performed to screen the effects of JS-K on MMP and TIMP production. The array profiles for JS-43-126-treated cells were similar to those of untreated cells (Figure $5 \mathrm{a}$ ). In contrast, the most consistent effect observed in the arrays of the three cell lines as a result of JS-K treatment was an increase in the production of TIMP-2 (Figure 5a). To confirm the JS-K-mediated increase in TIMP-2 levels that were observed in the MMP arrays, TIMP-2 ELISAs were performed. In MDA-MB-231 cells, TIMP-2 levels were increased $(P<0.05) 1.9$-fold and threefold at the 0.5 and $1 \mu \mathrm{M}$ doses of JS-K, respectively, while TIMP-2 was increased $(P<0.05) 1.5$-fold and 7.2 -fold in F10 cells at the same doses (Figure 5b). In MCF-7/COX-2 cells, TIMP-2 was increased $(P<0.05)$ only at the higher dose 
Figure 4

(a)

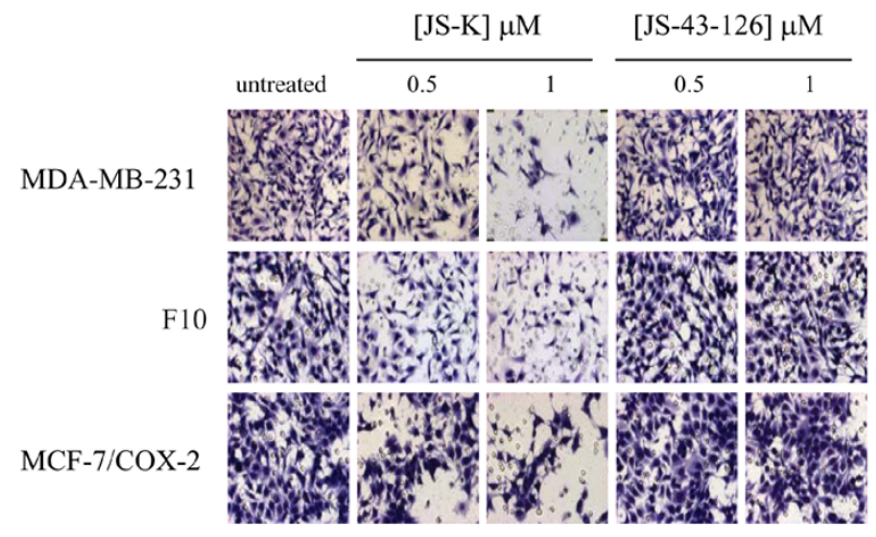

(c)

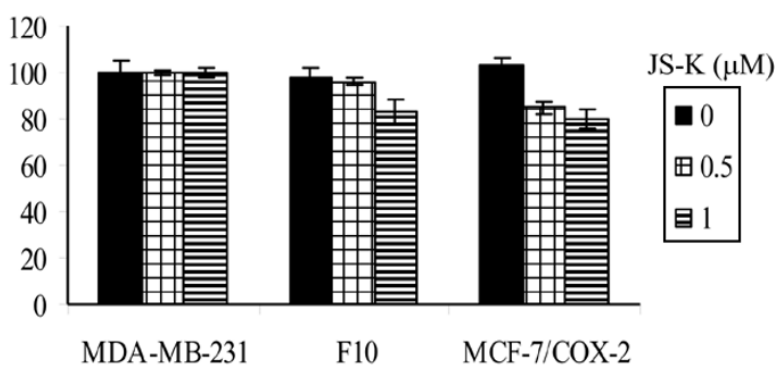

(b)

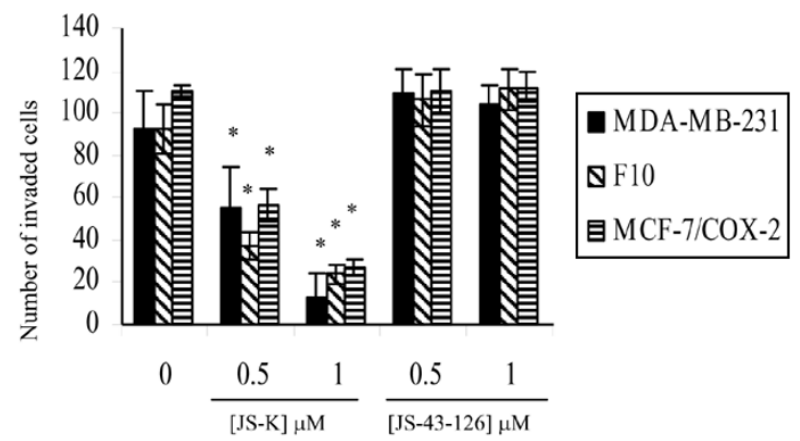

(d)

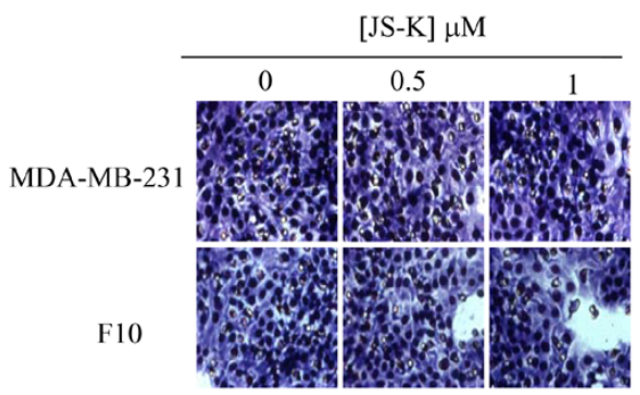

JS-K, but not JS-43-126, decreases the invasiveness of breast cancer cells across Matrigel. (a) MDA-MB-231, F10, and MCF-7/COX-2 cells were added into Matrigel-coated transwell inserts and incubated with JS-K or JS-43-126 for 72 hours. Cells that invaded through the pores onto the lower side of the filter were fixed, stained, and photographed. (b) The number of invaded cells for each filter was counted in five fields. The invasiveness of the cells is expressed as the mean number of cells that invaded to the lower side of the filter. Columns indicate the mean of triplicate wells \pm standard deviation. *Significant decrease in the number of invaded cells relative to untreated cells, $P<0.05$. (c) MDA-MB-231, F10, and MCF-7/COX-2 cells were plated on Matrigel-coated wells and incubated with JS-K. After 72 hours, cell proliferation was determined by Celltiter $96^{\circledR} A Q_{\text {ueous }}$ nonradioactive cell proliferation assay. Columns indicate the mean of pentaplicate wells \pm standard deviation. (d) MDA-MB-231 and F10 cells were added into type I collagen-coated transwell inserts and incubated with JS-K for 72 hours. Cells that invaded through the pores onto the lower side of the filter were fixed, stained, and photographed.

of JS-K (Figure 5b). TIMP-2 was increased $(P<0.05)$ twofold in MCF-7/COX-2 cells at the $1 \mu \mathrm{M}$ concentration of JS-K (Figure $5 b$ ). These data indicate that TIMP-2 may be the major, but not the only, target of JS-K.

Next we determined the importance of TIMP-2 in the anti-invasive effects of JS-K. To do this, TIMP-2 activity was blocked with a commercially available neutralizing antibody and the effect of JS-K on the invasiveness of MDA-MB-231, F10, and MCF-7/COX-2 cells across Matrigel was determined. At the concentration used, the anti-TIMP-2 antibody had no effect on invasion (Figure $5 \mathrm{c}, \mathrm{d}$ ). JS-K decreased the invasiveness of all cell lines across Matrigel; however, blocking TIMP-2 activity significantly $(P<0.05)$ suppressed the anti-invasive effects of JS-K (Figure 5c, d). In comparison with untreated MDA-MB231 cells, JS-K decreased $(P<0.05)$ the number of invaded cells by $72 \%$ and $37 \%$ in the absence and presence of the anti-TIMP-2 antibody, respectively (Figure $5 d$ ). The number of invaded $\mathrm{F} 10$ cells was $72 \%$ and $40 \%$ lower $(P<0.05)$ relative to untreated cells when treated with JS-K alone or in combination with the anti-TIMP-2 antibody, respectively (Figure $5 d$ ). JS-K decreased $(P<0.05)$ the number of invaded MCF-7/ COX-2 cells by $65 \%$, but in the presence of anti-TIMP-2 the number of invaded cells was decreased $(P<0.05)$ by $30 \%$ (Figure 5d). These data indicate that TIMP-2 is an important mediator of the anti-invasive activity of JS-K across the Matrigel basement membrane.

\section{JS-K decreases p38 activity in breast cancer cells}

Mitogen-activated protein kinase pathways, which have been shown to regulate TIMP-2 [36-38], are activated by JS-K $[16,17]$. We therefore determined whether these pathways were involved in JS-K-mediated TIMP-2 production. In all cell lines, p38 phosphorylation (indicative of activity) was unaffected by the $0.5 \mu \mathrm{M}$ concentration of JS-K (Figure 6). The 1.0 $\mu \mathrm{M}$ concentration of JS-K decreased $\mathrm{p} 38$ phosphorylation by 
Figure 5

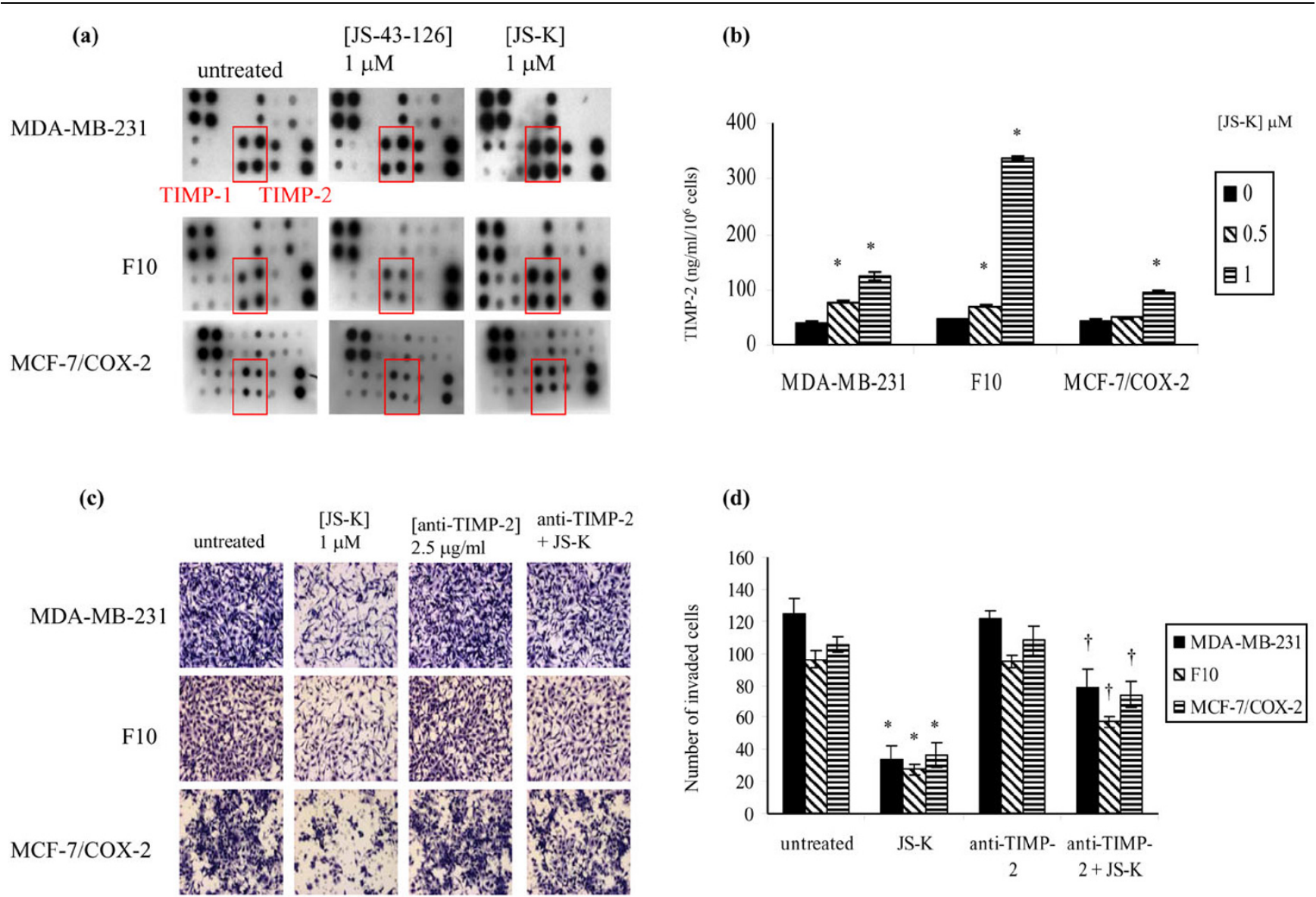

JS-K increases TIMP-2 production to suppress breast cancer invasion through Matrigel. (a) Expression of matrix metalloproteinases (MMPs) and tissue inhibitor of matrix metalloproteinases (TIMPs) in the conditioned medium supernatant obtained from untreated and JS-K-treated cells was qualitatively screened using a human MMP array kit. (b) TIMP-2 levels in the conditioned medium supernatant obtained from untreated and JS-K-treated cells were determined using a commercial ELISA kit. Columns indicate the mean of triplicate wells \pm standard deviation. *Significant increase in the TIMP-2 levels relative to untreated cells, $P<0.05$. (c) MDA-MB-231, F10, and MCF-7/COX-2 cells were treated with JS-K ( $1 \mu \mathrm{M})$ in the presence or absence of a TIMP-2 neutralizing antibody $(2.5 \mu \mathrm{g} / \mathrm{ml})$ for 72 hours in a Matrigel invasion assay. (d) The number of invaded cells was counted. Columns indicate the mean of triplicate wells \pm standard deviation. ${ }^{*}$ Significant decrease in the number of invaded cells relative to untreated cells, $P$ $<0.05$. ${ }^{\dagger}$ Increase relative to JS-K-treated cells, $P<0.05$.

approximately $27 \%, 62 \%$, and $70 \%$ in MDA-MB-231 cells, F10 cells, and MCF-7/COX-2 cells, respectively (Figure 6). At 0.5 and $1.0 \mu \mathrm{M}$ concentration, JS-K decreased ERK1/2 phosphorylation in F10 cells by $36 \%$ and $57 \%$, respectively (Figure 6). In contrast, JS-K did not affect ERK1/2 phosphorylation in MDA-MB-231 cells or MCF-7/COX-2 cells (Figure 6). The phosphorylation of JNK was not affected by JS-K in any cell line (Figure 6).

\section{Discussion}

JS-K is a NO prodrug that releases high levels of NO upon conjugation with glutathione by GST enzymes [15]. JS-K has been shown to inhibit the growth of cancer cells in vitro and in vivo [15-19]. In addition to its growth inhibitory properties, JS$K$ induces differentiation in leukemia cells [15] and possesses anti-angiogenic activity in vitro [16]. In the present study, we have identified inhibition of breast cancer invasion across the
Matrigel basement membrane as another important anticancer activity of JS-K.

Cell invasion involves MMP-mediated proteolysis of the basement membrane, which is counterbalanced by TIMPs. NO donors have been shown to increase and decrease MMP activity, depending on the cell type. NO donor-treated rheumatoid synovial cells increased MMP-2 production, but did not influence the production of TIMP-1 and TIMP-2 [39]. In human fibrosarcoma cells and lung epithelial cancer cells, NO donors inhibited MMP-2 secretion [40].

In the present study, JS-K increased TIMP-2 levels in breast cancer cells. TIMP-2 has been shown to inhibit the invasiveness of breast cancer cells in vitro and in vivo. Overexpression of TIMP-2 decreased the in vitro invasion of ras-transformed breast epithelial cells [41]. Mice injected with TIMP-2-trans- 


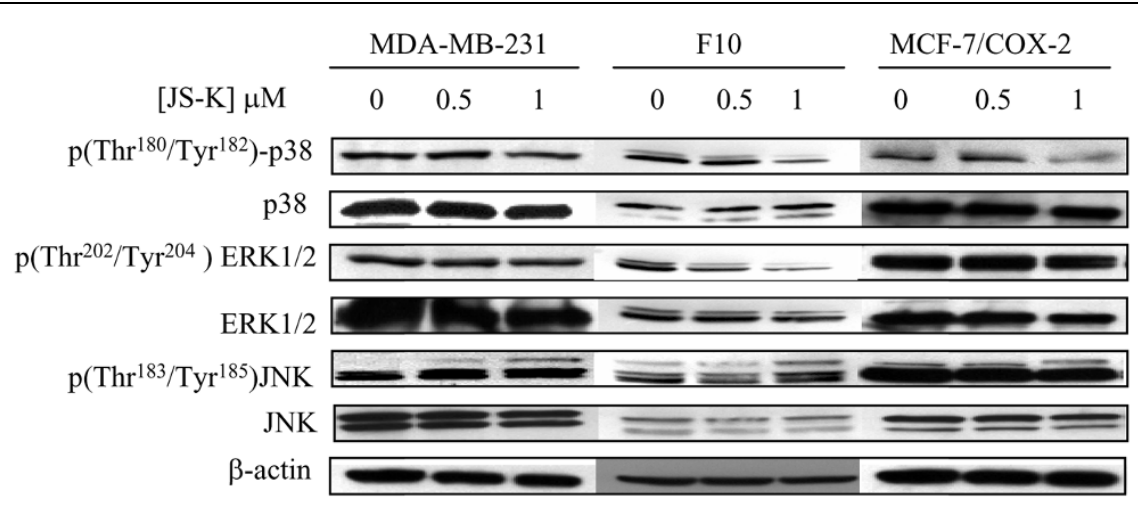

JS-K decreases p38 phosphorylation in breast cancer cells. Protein lysates were obtained from MDA-MB-231, F10, and MCF-7/COX-2 cells treated in the absence or presence of JS-K for 24 hours. Western blot analyses using phospho(Thr180/Tyr $\left.{ }^{182}\right)$-p38, p38, phospho(Thr202/Tyr ${ }^{204}$ )-extracellular signal-regulated kinase 1/2 (ERK1/2), ERK1/2, phospho(Thr183/Tyr ${ }^{185}$ )-c-Jun N-terminal kinase (JNK), and JNK antibodies were performed. $\beta$ actin was used as a loading control. Images were scanned and quantified. Ratios of phospho-p38 to total p38 levels in JS-K-treated cells were determined and compared with those in untreated cells. Ratios of phospho-ERK1/2 to total ERK1/2 levels in JS-K-treated F10 cells were determined and compared with those in untreated F10 cells.

fected MDA-MB-231 breast cancer cells had a lower number of osteolytic bone metastases and a higher survival rate than mice injected with nontransfected cells [42]. Liposome-complexed TIMP2 DNA constructs administered to MMTVneu transgenic mice reduced tumor growth and effectively inhibited the occurrence of lung metastases [43]. Our present findings are consistent with these of TIMP-2 acting as a suppressor of cell invasion. On the other hand, high levels of TIMP-2 have also been correlated with distant metastasis of breast tumors $[44,45]$. Our data indicate that TIMP-2 is an important mediator of the anti-invasive activity of JS-K. Since inhibition of TIMP-2 did not fully block the anti-invasive effects of JS-K, however, other mechanisms are likely to be involved in the anti-invasive effects of JS-K.

In the present study, JS-K was found to consistently decrease the activity of $\mathrm{p} 38$, but not that of ERK $1 / 2$ or JNK, in breast cancer cells. p38 has been shown to regulate TIMP-2 expression [37,38]. Downregulation of p38 activity increased TIMP2 production in squamous cell carcinoma [38]. Phorbol myristate acetate-induced downregulation of TIMP-2 secretion was reversed by inhibition of p38 in glioblastoma cells [36]. p38 activity was decreased only at the higher concentration of JS-K, however, despite the fact that JS-K inhibited the invasiveness of breast cell lines across Matrigel in a dose-dependent manner. p38 is not likely to be the major pathway involved in the anti-invasive activity of JS-K.

\section{Conclusion}

Our results reveal a novel and important function for the NOreleasing prodrug JS-K in suppressing the invasiveness of breast cancer cells across the Matrigel basement membrane. One mechanism by which JS-K inhibits breast cancer cell invasion is the upregulation of TIMP-2 production. The invasion of cancer cells through basement membrane is an essential step in cancer metastasis. The ability of JS-K to suppress this important step in the metastatic process indicates its potential clinical relevance in the chemoprevention and therapy of metastatic breast cancer.

\section{Competing interests}

The authors declare that they have no competing interests.

\section{Authors' contributions}

AMT and A-MS conceived and designed the study. AM-S, VM, and RN-A performed the proliferation assays, invasion assays, NO assays, MMP arrays, ELISAs, and western blot analyses. JES and LKK synthesized JS-K and JS-43-126. MMJ performed the statistical analysis. The manuscript was prepared by AM-S and AMT. All authors read, critically advised, and approved the manuscript.

\section{Acknowledgements}

The present study received financial support from the Cancer Research and Prevention Foundation (A-MS), the National Cancer Institute IDO1014 U54 RFA CA 096300 (AMT), the Intramural Research Program of the NIH, National Cancer Institute, Center for Cancer Research (LKK), and $\mathrm{NCl}$ Contract N01-CO12400 with SAIC-Frederick, Inc. (JES).

\section{References}

1. Ries L, Melbert D, Krapcho M: SEER Cancer Statistic Review, 1975-2004 2007 [http://seer.cancer.gov/csr/1975 2004/]. Bethesda, MD: National Cancer Institute

2. Orucevic A, Bechberger J, Green AM, Shapiro RA, Billiar TR, Lala PK: Nitric-oxide production by murine mammary adenocarcinoma cells promotes tumor-cell invasiveness. Int $J$ Cancer 1999, 81:889-896.

3. Jadeski LC, Hum KO, Chakraborty C, Lala PK: Nitric oxide promotes murine mammary tumour growth and metastasis by stimulating tumour cell migration, invasiveness and angiogenesis. Int J Cancer 2000, 86:30-39.

4. Xie K, Huang S, Dong Z, Juang SH, Gutman M, Xie OW, Nathan C, Fidler IJ: Transfection with the inducible nitric oxide synthase gene suppresses tumorigenicity and abrogates metas- 
tasis by K-1735 murine melanoma cells. J Exp Med 1995, 181:1333-1343.

5. Dhar A, Brindley JM, Stark C, Citro ML, Keefer LK, Colburn NH: Nitric oxide does not mediate but inhibits transformation and tumor phenotype. Mol Cancer Ther 2003, 2:1285-1293.

6. Gauthier N, Lohm S, Touzery C, Chantome A, Perette B, Reveneau $S$, Brunotte $F$, Juillerat-Jeanneret $L$, Jeannin JF: Tumour-derived and host-derived nitric oxide differentially regulate breast carcinoma metastasis to the lungs. Carcinogenesis 2004, 25:1559-1565.

7. Harada K, Supriatno, Kawaguchi S, Tomitaro O, Yoshida H, Sato $\mathrm{M}$ : Overexpression of iNOS gene suppresses the tumorigenicity and metastasis of oral cancer cells. In Vivo 2004, 18:449-455.

8. Le X, Wei D, Huang S, Lancaster JR Jr, Xie K: Nitric oxide synthase II suppresses the growth and metastasis of human cancer regardless of its up-regulation of protumor factors. Proc Natl Acad Sci USA 2005, 102:8758-8763.

9. Simeone A-M, Broemeling L, Rosenblum J, Tari AM: HER2/neu reduces the apoptotic effects of $\mathrm{N}$-(4-hydroxyphenyl)retinamide (4-HPR) in breast cancer cells by decreasing nitric oxide production. Oncogene 2003, 22:6739-6747.

10. Simeone A-M, Li YJ, Broemeling LD, Johnson MM, Tuna M, Tari AM: Cyclooxygenase-2 is essential for HER2/neu to suppress $\mathrm{N}$-(4-hydroxyphenyl)retinamide apoptotic effects in breast cancer cells. Cancer Res 2004, 64:1224-1228.

11. Howie AF, Miller WR, Hawkins RA, Hutchinson AR, Beckett GJ: Expression of glutathione S-transferase B1, B2, Mu and $\mathrm{Pi}$ in breast cancers and their relationship to oestrogen receptor status. Br J Cancer 1989, 60:834-837.

12. Shea TC, Claflin G, Comstock KE, Sanderson BJ, Burstein NA, Keenan EJ, Mannervik B, Henner WD: Glutathione transferase activity and isoenzyme composition in primary human breast cancers. Cancer Res 1990, 50:6848-6853.

13. Silvestrini R, Veneroni S, Benini E, Daidone MG, Luisi A, Leutner $M$, Maucione A, Kenda R, Zucali R, Veronesi U: Expression of p53, glutathione S-transferase-pi, and Bcl-2 proteins and benefit from adjuvant radiotherapy in breast cancer. $J$ Nat/ Cancer Inst 1997, 89:639-645.

14. Huang J, Tan $\mathrm{PH}$, Thiyagarajan J, Bay BH: Prognostic significance of glutathione S-transferase-pi in invasive breast cancer. Mod Pathol 2003, 16:558-565.

15. Shami PJ, Saavedra JE, Wang LY, Bonifant CL, Diwan BA, Singh SV, Gu Y, Fox SD, Buzard GS, Citro ML, Waterhouse DJ, Davies $\mathrm{KM}$, Ji X, Keefer LK: JS-K, a glutathione/glutathione S-transferase-activated nitric oxide donor of the diazeniumdiolate class with potent antineoplastic activity. Mol Cancer Ther 2003, 2:409-417.

16. Shami PJ, Saavedra JE, Bonifant CL, Chu J, Udupi V, Malaviya S, Carr BI, Kar S, Wang M, Jia L, Jia L, Ji X, Keefer LK: Antitumor activity of JS-K [O2-(2,4-dinitrophenyl) 1-[(4-ethoxycarbonyl)piperazin-1-yl]diazen-1-ium-1,2-diolate] and related $\mathrm{O}^{2-}$ aryl diazeniumdiolates in vitro and in vivo. J Med Chem 2006, 49:4356-4366.

17. Ren Z, Kar S, Wang Z, Wang M, Saavedra JE, Carr BI: JS-K, a novel non-ionic diazeniumdiolate derivative, inhibits Hep 3B hepatoma cell growth and induces c-Jun phosphorylation via multiple MAP kinase pathways. J Cell Physiol 2003, 197:426-434.

18. Udupi V, Yu M, Malaviya S, Saavedra JE, Shami PJ: JS-K, a nitric oxide prodrug, induces cytochrome $c$ release and caspase activation in HL-60 myeloid leukemia cells. Leuk Res 2006, 30:1279-1283.

19. Kiziltepe T, Hideshima T, Ishitsuka K, Ocio EM, Raje N, Catley L, Li $\mathrm{CQ}$, Trudel $\sqcup$, Yasui $\mathrm{H}$, Vallet $S$, Kutok JL, Chauhan D, Mitsiades CS, Saavedra JE, Wogan GN, Keefer LK, Shami PJ, Anderson KK: JS-K, a GST-activated nitric oxide generator, induces DNA double-strand breaks, activates DNA damage response pathways, and induces apoptosis in vitro and in vivo in human multiple myeloma cells. Blood 2007, 110:709-718.

20. Saavedra JE, Srinivasan A, Bonifant $C L$, Chu J, Shanklin AP, Flippen-Anderson JL, Rice WG, Turpin JA, Davies KM, Keefer LK: The secondary amine/nitric oxide complex ion $\mathrm{R}(2) \mathrm{N}[\mathrm{N}(\mathrm{O}) \mathrm{NO}$ (-) as nucleophile and leaving group in $\mathrm{S} 9 \mathrm{~N}) \mathrm{Ar}$ reactions. J Org Chem 2001, 66:3090-3098.

21. Mackay M, Gale D, Wilshire J: Structural studies of some 1polymethyleneimino-2,4-dinitrobenzenes and related com- pounds; crystal structure of 1-(cis-2',6'-dimethylpiperidin-1'yl)-2,4-dinitrobenzene. Aust J Chem 2000, 53:715-722.

22. Yoneda T, Williams PJ, Hiraga T, Niewolna M, Nishimura R: A bone-seeking clone exhibits different biological properties from the MDA-MB-231 parental human breast cancer cells and a brain-seeking clone in vivo and in vitro. J Bone Miner Res 2001, 16:1486-1495

23. Costa C, Soares R, Reis-Filho J, Leitao D, Amendoeira I, Schmitt $\mathrm{F}$ : Cyclo-oxygenase 2 expression is associated with angiogenesis and lymph node metastasis in human breast cancer. $J$ Clin Pathol 2002, 55:429-434.

24. Denkert $C$, Winzer KJ, Muller BM, Weichert W, Pest S, Kobel M, Kristiansen G, Reles A, Siegert A, Guski H, Hauptmann S: Elevated expression of cyclooxygenase- 2 is a negative prognostic factor for disease free survival and overall survival in patients with breast carcinoma. Cancer 2003, 97:2978-2987.

25. Zhang $X H$, Huang DP, Guo GL, Chen GR, Zhang HX, Wan L, Chen SY: Coexpression of VEGF-C and COX-2 and its association with lymphangiogenesis in human breast cancer. $B M C$ Cancer 2008, 8:4.

26. Tari AM, Simeone AM, Li YJ, Gutierrez-Puente Y, Lai S, Symmans WF: Cyclooxygenase-2 protein reduces tamoxifen and $\mathrm{N}-(4-$ hydroxyphenyl)retinamide inhibitory effects in breast cancer cells. Lab Invest 2005, 85:1357-1367.

27. Simeone AM, Nieves-Alicea R, McMurtry VC, Colella S, Krahe R, Tari AM: Cyclooxygenase-2 uses the protein kinase $\mathrm{C} /$ interleukin-8/urokinase-type plasminogen activator pathway to increase the invasiveness of breast cancer cells. Int $J$ Oncol 2007, 30:785-792.

28. Simeone A-M, Colella S, Krahe R, Johnson MM, Mora E, Tari AM: $\mathrm{N}$-(4-Hydroxyphenyl)retinamide and nitric oxide pro-drugs exhibit apoptotic and anti-invasive effects against bone metastatic breast cancer cells. Carcinogenesis 2006, 27:568-577.

29. Hendrix MJ, Seftor EA, Seftor RE, Fidler IJ: A simple quantitative assay for studying the invasive potential of high and low human metastatic variants. Cancer Lett 1987, 38:137-147.

30. Albini A, Iwamoto Y, Kleinman HK, Martin GR, Aaronson SA Kozlowski JM, McEwan RN: A rapid in vitro assay for quantitating the invasive potential of tumor cells. Cancer Res 1987, 47:3239-3245.

31. Terranova VP, Hujanen ES, Loeb DM, Martin GR, Thornburg L, Glushko V: Use of a reconstituted basement membrane to measure cell invasiveness and select for highly invasive tumor cells. Proc Natl Acad Sci USA 1986, 83:465-469.

32. Coleman RE: Clinical features of metastatic bone disease and risk of skeletal morbidity. Clin Cancer Res 2006, 12:6243s-6249s.

33. Buckwalter JA, Glimcher MJ, Cooper RR, Recker R: Bone biology. I: structure, blood supply, cells, matrix, and mineralization. Instr Course Lect 1996, 45:371-386.

34. Hall CL, Dai J, van Golen KL, Keller ET, Long MW: Type I collagen receptor (alpha 2 beta 1 ) signaling promotes the growth of human prostate cancer cells within the bone. Cancer Res 2006, 66:8648-8654

35. Nabha SM, dos Santos EB, Yamamoto HA, Belizi A, Dong Z, Meng $\mathrm{H}$, Saliganan A, Sabbota A, Bonfil RD, Cher ML: Bone marrow stromal cells enhance prostate cancer cell invasion through type I collagen in an MMP-12 dependent manner. Int $J$ Cancer 2008, 122:2482-2490.

36. Park MJ, Park IC, Hur JH, Kim MS, Lee HC, Woo SH, Lee KH, Rhee $\mathrm{CH}$, Hong SI, Lee SH: Modulation of phorbol esterinduced regulation of matrix metalloproteinases and tissue inhibitors of metalloproteinases by SB20 a specific inhibitor of p38 mitogen-activated protein kinase. J Neurosurg 3580 97:112-118.

37. Horiuchi $H$, Kawamata $H$, Furihata $T$, Omotehara $F$, Hori $H$, Shinagawa $Y$, Ohkura Y, Tachibana M, Yamazaki T, Ajiki T, Kuroda $Y$, Fujimori T: A MEK inhibitor (U0126) markedly inhibits direct liver invasion of orthotopically inoculated human gallbladder cancer cells in nude mice. J Exp Clin Cancer Res 2004, 23:599-606.

38. Munshi HG, Wu YI, Mukhopadhyay S, Ottaviano AJ, Sassano A, Koblinski JE, Platanias LC, Stack MS: Differential regulation of membrane type 1-matrix metalloproteinase activity by ERK 1/ 2- and p38 MAPK-modulated tissue inhibitor of metalloproteinases 2 expression controls transforming growth factor- 
beta1-induced pericellular collagenolysis. J Biol Chem 2004, 279:39042-39050.

39. Hirai Y, Migita K, Honda S, Ueki Y, Yamasaki S, Urayama S, Kamachi M, Kawakami A, Ida H, Kita M, Fukuda T, Shibatomi K, Kawabe A, Aoyagi T, Eguchi K: Effects of nitric oxide on matrix metalloproteinase-2 production by rheumatoid synovial cells. Life Sci 2001, 68:913-920.

40. Jurasz P, Sawicki G, Duszyk M, Sawicka J, Miranda C, Mayers I, Radomski MW: Matrix metalloproteinase 2 in tumor cellinduced platelet aggregation: regulation by nitric oxide. Cancer Res 2001, 61:376-382.

41. Ahn SM, Jeong SJ, Kim YS, Sohn Y, Moon A: Retroviral delivery of TIMP-2 inhibits $\mathrm{H}$-ras-induced migration and invasion in MCF10A human breast epithelial cells. Cancer Lett 2004, 207:49-57.

42. Yoneda T, Sasaki A, Dunstan C, Williams PJ, Bauss F, De Clerck YA, Mundy GR: Inhibition of osteolytic bone metastasis of breast cancer by combined treatment with the bisphosphonate ibandronate and tissue inhibitor of the matrix metalloproteinase-2. J Clin Invest 1997, 99:2509-2517.

43. Sacco MG, Soldati S, Indraccolo S, Cato EM, Cattaneo L, Scanziani $E$, Vezzoni $P$ : Combined antiestrogen, antiangiogenic and anti-invasion therapy inhibits primary and metastatic tumor growth in the MMTVneu model of breast cancer. Gene Ther 2003, 10:1903-1909.

44. Ree AH, Florenes VA, Berg JP, Maelandsmo GM, Nesland JM, Fodstad O: High levels of messenger RNAs for tissue inhibitors of metalloproteinases (TIMP-1 and TIMP-2) in primary breast carcinomas are associated with development of distant metastases. Clin Cancer Res 1997, 3:1623-1628.

45. Vizoso FJ, Gonzalez LO, Corte MD, Rodriguez JC, Vazquez J, Lamelas ML, Junquera S, Merino AM, Garcia-Muniz JL: Study of matrix metalloproteinases and their inhibitors in breast cancer. Br J Cancer 2007, 96:903-911. 